\title{
BMJ Open Association between in-hospital guideline adherence and postdischarge major adverse outcomes of patients with acute coronary syndrome in Vietnam: a prospective cohort study
}

\author{
Thang Nguyen, ${ }^{1,2}$ Khanh K Le, ${ }^{1}$ Hoang T K Cao, ${ }^{1}$ Dao T T Tran, ${ }^{1}$ Linh M Ho, ${ }^{1}$ \\ Trang N D Thai, ${ }^{1}$ Hoa T K Pham, ${ }^{3}$ Phong T Pham, ${ }^{4}$ Thao H Nguyen, ${ }^{5}$ Eelko Hak, ${ }^{2}$ \\ Tam T Pham, ${ }^{6}$ Katja Taxis ${ }^{2}$
}

To cite: Nguyen T, Le KK, Cao HTK, et al. Association between in-hospital guideline adherence and postdischarge major adverse outcomes of patients with acute coronary syndrome in Vietnam: a prospective cohort study. BMJ Open 2017;7:e017008. doi:10.1136/ bmjopen-2017-017008

- Prepublication history and additional material for this paper are available online. To view these files, please visit the journal online (http://dx.doi. org/10.1136/bmjopen-2017017008).

Received 27 March 2017 Revised 5 July 2017 Accepted 2 August 2017

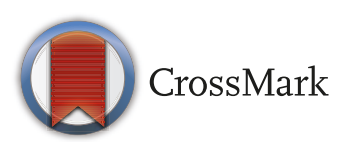

For numbered affiliations see end of article.

Correspondence to

Thang Nguyen;

nthang@ctump.edu.vn

\section{ABSTRACT}

Objective We aimed to determine the association between physician adherence to prescribing guidelinerecommended medications during hospitalisation and 6-month major adverse outcomes of patients with acute coronary syndrome in Vietnam.

Design Prospective cohort study.

Setting The study was carried out in two public hospitals in Vietnam between January and October 2015. Patients were followed for 6 months after discharge.

Participants Patients who survived during hospitalisation with a discharge diagnosis of acute coronary syndrome and who were eligible for receiving at least one of the four guideline-recommended medications.

Exposures Guideline adherence was defined as prescribing all guideline-recommended medications at both hospital admission and discharge for eligible patients. Medications were antiplatelet agents, beta-blockers, ACE inhibitors or angiotensin II receptor blockers and statins.

Main outcome measure Six-month major adverse outcomes were defined as all-cause mortality or hospital readmission due to cardiovascular causes occurring during 6 months after discharge. Cox regression models were used to estimate the association between guideline adherence and 6-month major adverse outcomes. Results Overall, 512 patients were included. Of those, there were 242 patients (47.3\%) in the guideline adherence group and 270 patients $(52.3 \%)$ in the nonadherence group. The rate of 6-month major adverse outcomes was $30.5 \%$. A $29 \%$ reduction in major adverse outcomes at 6 months after discharge was found for patients of the guideline adherence group compared with the non-adherence group (adjusted HR, 0.71; 95\% Cl, 0.51 to $0.98 ; p=0.039$ ). Covariates significantly associated with the major adverse outcomes were percutaneous coronary intervention, prior heart failure and renal insufficiency. Conclusions In-hospital guideline adherence was associated with a significant decrease in major adverse outcomes up to 6 months after discharge. It supports the need for improving adherence to guidelines in hospital practice in low-income and middle-income countries like Vietnam.
Strengths and limitations of this study

- This is the first prospective cohort study to evaluate the association between physician performance and patients' adverse outcomes in Vietnam, a lower middle-income country in Asia.

- Estimation of the sample size was not possible because previous studies identifying the association between in-hospital guideline adherence and postdischarge major adverse outcomes in lowincome and middle-income countries like Vietnam were not available.

- Although we attempted to address the impact of in-hospital guideline adherence on postdischarge adverse outcomes by adjusting for potential factors, the possibility of confounding by unmeasured covariates remains.

\section{INTRODUCTION}

Ischaemic heart diseases (IHDs) are the leading cause of death worldwide, accounting for $13.2 \%$ of all deaths globally. ${ }^{1}$ More than $80 \%$ of those occur in low-income and middle-income countries. ${ }^{2}$ IHDs comprise a spectrum of diseases of the heart including stable angina and acute coronary syndrome (ACS) which is the dominant cause of IHD deaths. ${ }^{3}$ In Vietnam, ACS is also one of the leading causes of mortality. ${ }^{4}$ International guidelines recommend using a combination of an antiplatelet agent, a beta-blocker, an ACE inhibitor or an angiotensin II receptor blocker (ACEI/ARB) and a statin to treat eligible patients with ACS. ${ }^{5-8}$ The Vietnam National Heart Association (VNHA) guidelines $^{9}$ are in line with the international guidelines. ${ }^{5-8}$

Adherence to guidelines remains suboptimal in clinical practice, ${ }^{10-13}$ in particular, 
in low-income and middle-income countries. ${ }^{14-16}$ In fact, in-hospital guideline adherence for patients with ACS in Vietnam was suboptimal. ${ }^{17}$ Prescribing of guideline-recommended medications has been shown to reduce both in-hospital and postdischarge morbidity and mortality. ${ }^{18-22}$ The impact of guideline adherence on mortality of patients with ACS during hospitalisation has been determined previously. ${ }^{23}$ Less data are available on the association between in-hospital guideline adherence and postdischarge major adverse outcomes in patients with ACS, especially from low-income and middle-income countries like Vietnam.

Therefore, we aimed to determine the association between in-hospital guidelines adherence and 6-month postdischarge major adverse outcomes of patients with ACS in Vietnam.

\section{METHODS}

\section{Setting and study population}

We conducted a prospective cohort study of patients discharged with a diagnosis of ACS. Patients were followed for 6 months after discharge. We selected the two largest public hospitals (central and provincial level) in the centre of Can Tho City, Vietnam with facilities to treat ACS. Within the region, these two hospitals provide the highest level of care to patients with ACS. Percutaneous coronary intervention (PCI) could be performed in the central hospital only. Study hospital wards were cardiac wards, intensive care units and cardiac interventional unit.

All eligible patients admitted to the study wards between January and October 2015 were approached for participation. The follow-up period ended in April 2016. We included patients who survived during hospitalisation with one of the following discharge diagnoses according to the coding of the International Classification of Diseases, 10th revision: unstable angina (I20.0), acute myocardial infarction (I21) or subsequent myocardial infarction (I22). ${ }^{24}$ Patients had to be eligible for receiving at least one of the four guideline-recommended medications. For patients who were admitted several times during the study period, we only included the first admission. We excluded patients (1) who had been admitted to another hospital initially and were transferred to the study site consequently; (2) who did not fully complete treatment therapy (ie, transferred to another hospital for further treatment, discharged without permission of their physicians, or discharged without a prescription because of severe illness); (3) or with missing data of treatment at hospital admission or discharge in their medical records.

The study was approved by the institutional review boards of the Can Tho Central General Hospital and Can Tho General Hospital in Can Tho City, Vietnam. Verbal consent was obtained from all participants by one of the researchers responsible for data collection (DTTT, LMH and TNDT). The researchers explained the main objective of the study and outlined all procedures involved to the patients and relatives/carers (if present). They were emphasised that participation did not affect their care, was voluntary and they could withdraw at any point in the study. This procedure was approved by the institutional review boards and is in line with Vietnamese regulations.

\section{Data sources and data}

Three researchers (DTTT, LMH and TNDT) collected data from medical records and patient interviews. Patients' medical records were requested from the medical record archives of the two study hospitals using a predefined data collection form. Baseline data included demographic characteristics, coronary artery disease (CAD) risk factors, medical history and comorbidities, discharge diagnoses, hospital findings and undergoing PCI during hospitalisation. Hospital findings comprised Killip class, estimated glomerular filtration rate (eGFR), heart rate, systolic blood pressure (SBP), left ventricular ejection fraction (LVEF), atrial ventricular (AV) block, aspartate aminotransferase or alanine aminotransferase (AST/ALT) levels and in-hospital bleeding. Details of all medications prescribed within the first 24 hours after hospital admission and at hospital discharge were collected. Information on the contraindications to antiplatelet agents, beta-blockers, ACEIs/ARBs or statins was also recorded. Researchers asked physicians if baseline data were missing in the medical records.

During the follow-up period, patients, their relatives or both were interviewed twice to collect information on major adverse outcomes. The first interview took place on day 31 (or within 2 weeks) after discharge and the second on day 181 (or within 2 weeks) after discharge. The end of the follow-up period was either the date of 6 months after discharge or the date of death, whichever occurred first.

\section{Guideline adherence}

Guideline adherence was defined as prescribing all guideline-recommended medications at both hospital admission and discharge for patients eligible to receive the medications. Guidelines used in the study were the current version of the VNHA, ${ }^{9}$ the European Society of Cardiology ${ }^{78}$ and the American College of Cardiology/ American Heart Association. ${ }^{5} 6$ All three guidelines recommend the use of an antiplatelet agent (aspirin, clopidogrel or both), a beta-blocker, an ACEI/ARB and a statin within the first 24 hours after hospital admission and at hospital discharge. We have described the criteria to be eligible for being prescribed the medications elsewhere. ${ }^{17}$ Briefly, patients eligible for being prescribed an antiplatelet agent, a beta-blocker or a statin were all patients who did not have contraindications to the medications. Patients eligible for being prescribed an ACEI/ $\mathrm{ARB}$ were patients with prior heart failure, an $\mathrm{LVEF}<40 \%$, diabetes mellitus or hypertension, and no contraindications to the medication. Patients were stratified into two groups, exposed and unexposed to guideline adherence. Hereafter, the exposed group was called 'guideline 
adherence group', and the unexposed group was called 'guideline non-adherence group'.

\section{Outcomes}

Six-month major adverse outcomes were defined as all-cause mortality or hospital readmission due to cardiovascular causes (including ACS, stroke or any related cardiovascular diseases) occurring during 6 months after discharge.

\section{Covariates}

Covariates were identified because they are associated with risk of major adverse outcomes or with the likelihood of guideline adherence. The covariates might confound the association between guideline adherence and major adverse outcomes. The covariates associated with major adverse outcomes were based on relevant studies. They were age, ${ }^{25}{ }^{26}$ gender, ${ }^{27} 28$ discharge diagnosis (non-ST-elevation acute coronary syndrome (NSTEACS) or ST-elevation acute coronary syndrome (STEACS) ), ${ }^{29}{ }^{30}$ prior myocardial infarction/stroke, ${ }^{31} 32$ prior heart failure, ${ }^{33-36}$ renal insufficiency (eGFR $<60$ or $\left.\geq 60 \mathrm{~mL} / \mathrm{min} / 1.73 \mathrm{~m}^{2}\right),{ }^{35-37}$ the number of CAD risk factors (including CAD family history, hypertension, diabetes, dyslipidemia and smoking), ${ }^{37}$ Killip class (I or $\geq \mathrm{II}$ ), ${ }^{38} 39$ SBP $(<100$ or $\geq 100 \mathrm{~mm} \mathrm{Hg}),{ }^{40}$ LVEF $(<40 \% \text { or } \geq 40 \%)^{41}$ and PCI (undergoing or not). ${ }^{42-46}$ The covariates associated with the likelihood of guideline adherence were identified based on the differences in characteristics between guideline adherence and non-adherence groups. The cut-offs of continuous covariates were based on clinical relevance. ${ }^{5-9} 17$

\section{Statistical methods}

Data were presented as absolute numbers, percentages, means with SDs or medians with IQRs as appropriate. The frequencies of categorical variables of two patient groups were compared using the $\chi^{2}$ test or Fisher's exact test. Continuous variables were compared using Student's t-test or Mann-Whitney test. A univariable Cox regression model was used to estimate the unadjusted HR with $95 \%$ CI of the association between in-hospital guideline adherence and 6-month major adverse outcomes, and to explore the nature of the association based on type and number of guideline-recommended medications. Multivariable backward stepwise Cox regression models were used to estimate the association. The first model was adjusted for the covariates and the second model was adjusted for significant associated factors of the first model and interaction terms between these factors and guideline adherence. Also Kaplan-Meier curves of surviving and not being readmitted due to cardiovascular causes were generated. In addition, we explored the impact of attrition bias due to dropouts in sensitivity analyses using multiple imputations to impute missing outcomes and repeating the analyses on the basis of an imputed sample of all patients included at baseline. We also performed sensitivity analyses excluding potential covariates affecting the major adverse outcomes. Furthermore, we performed subgroup analyses based on dropout status in order to compare the differences in baseline and treatment characteristics which could bias the association. All tests were two-sided. p Values of 0.05 or less were considered statistically significant. Analyses were performed using the Statistical Package for the Social Sciences, V24 (SPSS 24).

\section{RESULTS}

Of 706 hospital admissions due to ACS at baseline, 610 (86.4\%) patients were included; and 96 hospital admissions $(13.6 \%)$ were excluded due to the following reasons: in-hospital death (1 case), severely ill without a discharge prescription (21), transfer to another hospital (44), second admission (29) and patient record not being available (1). There were 328 included patients (53.8\%) in the guideline non-adherence group and 282 included patients $(46.2 \%)$ in the adherence group. There were 58 dropouts $(17.7 \%)$ in the non-adherence and 40 dropouts $(14.2 \%)$ in the adherence group. In total, 512 patients completed the follow-up and were included in our analysis. Reasons for the dropouts were not available because we could not contact patients or their relatives (figure 1).

The median age (IQR) was 68 years (59 to 79 ), $54.7 \%$ were males and $79.7 \%$ had social health insurance. The majority of patients had hypertension (80.3\%) and a discharge diagnosis of NSTEACS (68.6\%), and did not undergo PCI (75.0\%). Documented contraindications were in-hospital gastrointestinal bleeding (for antiplatelet agents); asthma/chronic obstructive pulmonary disease (COPD), Killips class II-IV, heart rate $<60$ beats/ min, $\mathrm{SBP}<100 \mathrm{~mm} \mathrm{Hg}, \mathrm{LVEF}<40 \%$ and AV block II-III (beta-blockers); $\mathrm{SBP}<100 \mathrm{~mm} \mathrm{Hg}$ and eGFR $<30 \mathrm{~mL} /$ $\mathrm{min} / 1.73 \mathrm{~m}^{2}$ (ACEIs/ARBs); an increase of AST/ALT greater than three times the upper limit of normal (statins). There was a significant difference between the two groups in several characteristics: social health insurance, Killip class II-IV, SBP $<100 \mathrm{~mm} \mathrm{Hg}$ and $\mathrm{LVEF}<40 \%$ (table 1).

There was guideline adherence in 242 patients (47.3\%) and non-adherence in 270 patients $(52.7 \%)$. The rate of 6-month major adverse outcomes, mortality and hospital readmission were $30.5 \%, 12.0 \%$ and $23.6 \%$, respectively. Six-month major adverse outcomes were significantly lower $(\mathrm{p}=0.014)$ in the guideline adherence group $(25.2 \%)$ compared with those in the non-adherence group $(35.2 \%)$. Mortality (10.6\% vs $13.1 \%)$ and hospital readmission $(19.8 \%$ vs $27.0 \%)$ were not statistically significant between the adherence and the non-adherence group.

Patients in the guideline adherence group had a lower risk of major adverse outcomes in univariable analysis (unadjusted HR=0.69; 95\% CI 0.50 to $0.95 ; \mathrm{p}=0.021$ ) (table 2) and in multivariable analysis (adjusted $\mathrm{HR}=0.71$; 95\% CI 0.51 to $0.98 ; \mathrm{p}=0.039$ ) after adjusting for PCI, prior heart failure and renal insufficiency (table 3 and figure 2). Patients had a lower risk of major adverse 


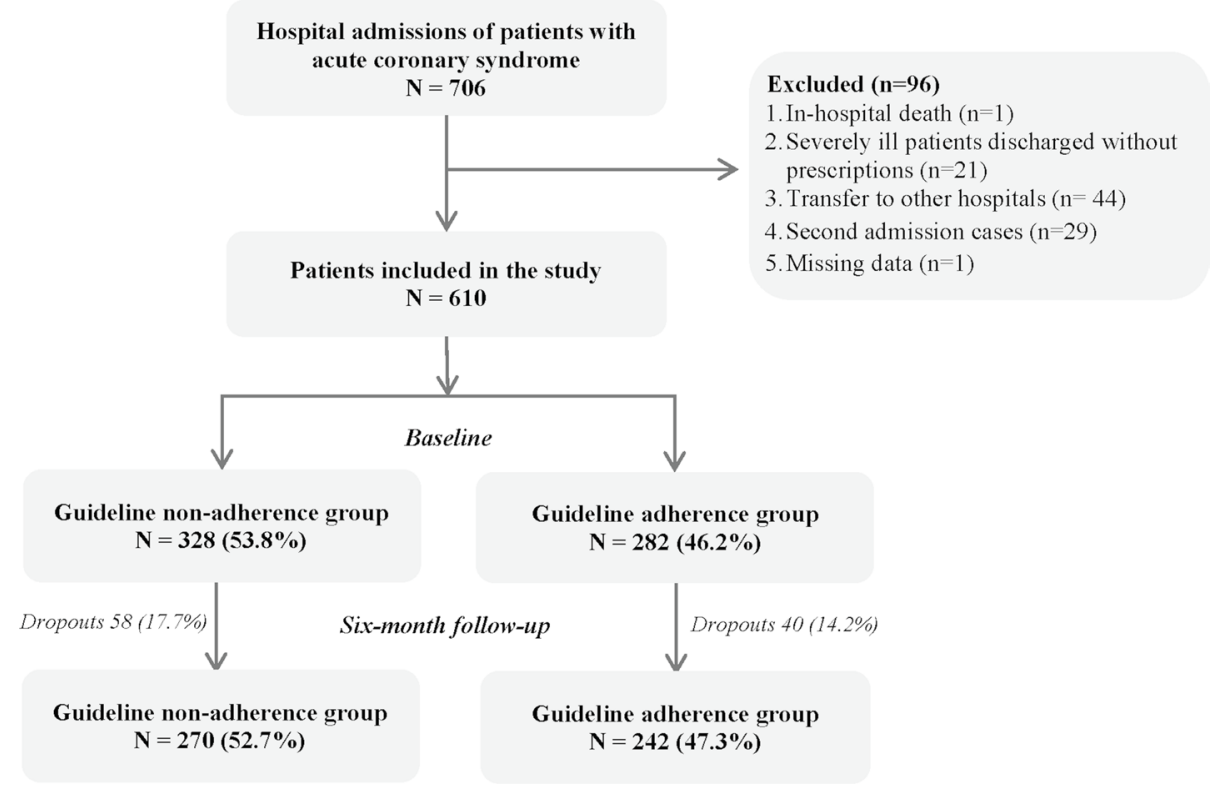

Figure 1 Flowchart of study population

outcomes when they received beta-blockers (unadjusted $\mathrm{HR}=0.46 ; 95 \%$ CI 0.29 to $0.72 ; \mathrm{p}=0.001$ ), or all four medications (unadjusted HR $=0.37 ; 95 \%$ CI 0.20 to 0.66 ; $\mathrm{p}=0.001$ ) $.31 .7 \%$ of patients received all four medications according to the guidelines (table 2). Patients undergoing PCI had a lower risk of major adverse outcomes (adjusted $\mathrm{HR}=0.60 ; 95 \%$ CI 0.38 to $0.95 ; \mathrm{p}=0.024$ ). Patients had a higher risk of major adverse outcomes when they had prior heart failure (adjusted $\mathrm{HR}=1.92 ; 95 \%$ CI 1.36 to 2.69; $\mathrm{p}<0.001$ ) or renal insufficiency (adjusted $\mathrm{HR}=1.38$; $95 \%$ CI 1.00 to $1.91 ; \mathrm{p}=0.050$ ) (table 3 ).

Subgroup analyses revealed that patients completing the follow-up compared with those dropping out were less likely to smoke and to receive antiplatelet agents, statins, at least two guideline-recommended medications (online supplementary appendix 1 ). In sensitivity analyses, patients in the guideline adherence group had a lower risk of major adverse outcomes after imputing dropouts' censoring time and event occurrence (pooled $\mathrm{HR}=0.66 ; 95 \%$ CI 0.48 to $0.92 ; \mathrm{p}=0.015$ ), or excluding patients who underwent PCI (HR=0.70; $95 \%$ CI 0.49 to $0.99 ; \mathrm{p}=0.046)$, who had prior heart failure $(\mathrm{HR}=0.56$; $95 \%$ CI 0.36 to $0.89 ; \mathrm{p}=0.013)$ or who had renal insufficiency $(\mathrm{HR}=0.56 ; 95 \% \mathrm{CI} 0.35$ to $0.92 ; \mathrm{p}=0.021)$ (online supplementary appendix 2).

\section{DISCUSSION}

\section{Principal findings}

About half of patients were prescribed all medications according to guidelines. In about one-third of patients, a major adverse outcome occurred within 6 month of discharge. We found a $29 \%$ reduction in major adverse outcomes at 6 months after discharge for patients who received medications according to guidelines compared with those who did not. Prior heart failure, renal insufficiency or not receiving PCI also significantly increased the risk of major adverse outcomes.

\section{Strengths and weaknesses of the study}

As far as we are aware, no work has been done to evaluate the benefits of guideline adherence in treatment for patients with ACS in Vietnam or similar low-income and middle-income countries. The major strengths are the prospective cohort design to evaluate the association between physician performance and patients' adverse outcomes in Vietnam, a middle-income Asian country. Both unadjusted and adjusted HRs showed similar benefits of in-hospital guideline adherence. However, our study was conducted in two hospitals in one of 63 cities in Vietnam ${ }^{4}$; this potentially limited the generalisability of our findings. Nevertheless, our study included hospitals with and without onsite invasive procedures and prospectively followed patients for 6 months.

Several issues in our study should be considered. First, we only had information on therapies during the index hospitalisation and did not have data on the use of guideline-recommended medications during follow-up, nor did we have data postdischarge on follow-up visits, side effects and the duration of the medical therapy, patients' adherence to treatment and lifestyle modification. All of these might influence postdischarge adverse outcomes. Second, although our study included patients without contraindications to guideline-recommended medications, physicians may have had concerns about adverse effects of these medications in some cases. For example, it has been shown that physicians were very cautious about prescribing a beta-blocker at discharge for older patients with ACS and diabetes, ${ }^{47} 48$ especially to patients living alone, not having an informal care provider. Differences between hospitals and physicians in the quality of care other than prescribing according 
Table 1 Baseline characteristics of patients

\begin{tabular}{|c|c|c|c|c|}
\hline \multirow[b]{2}{*}{ Patient characteristic } & \multirow{2}{*}{$\begin{array}{l}\text { Overall } \\
(n=512)\end{array}$} & \multicolumn{2}{|c|}{ Study group } & \multirow[b]{2}{*}{ p Value ${ }^{x}$} \\
\hline & & Non-adherence $(n=270)$ & Adherence $(n=242)$ & \\
\hline \multicolumn{5}{|l|}{ General characteristics } \\
\hline Age, median (IQR) years & $68(59 ; 79)$ & $70(59 ; 80)$ & $66(59 ; 79)$ & $0.160 \dagger$ \\
\hline Age $\geq 65, n(\%)$ & $298(58.2)$ & $166(61.5)$ & $132(54.5)$ & 0.112 \\
\hline Male, n (\%) & $280(54.7)$ & $139(51.5)$ & $141(58.3)$ & 0.124 \\
\hline Health insurance, $\mathrm{n}(\%)$ & $408(79.7)$ & $229(84.8)$ & $179(74.0)$ & 0.002 \\
\hline Hospital length of stay, median (IQR) days & $9(7 ; 12)$ & $9(7 ; 12)$ & $9(7 ; 12)$ & $0.811 \dagger$ \\
\hline \multicolumn{5}{|l|}{ CAD risk factors } \\
\hline CAD family history, $\mathrm{n}(\%)$ & $29(5.7)$ & $17(6.3)$ & $12(5.0)$ & 0.513 \\
\hline Hypertension, $\mathrm{n}(\%)$ & $411(80.3)$ & $220(81.5)$ & $191(78.9)$ & 0.468 \\
\hline Diabetes, n (\%) & $119(23.2)$ & $66(24.4)$ & $53(21.9)$ & 0.496 \\
\hline Dyslipidemia, n (\%) & $127(24.8)$ & $68(25.5)$ & $59(24.4)$ & 0.833 \\
\hline Smoking, n (\%) & $196(38.3)$ & $100(37.0)$ & $96(39.7)$ & 0.541 \\
\hline Number of CAD risk factors, median (IQR) & $2(1 ; 2)$ & $2(1 ; 2)$ & $2(1 ; 2)$ & $0.643 \dagger$ \\
\hline \multicolumn{5}{|l|}{ Medical history and comorbidities, n (\%) } \\
\hline Prior Ml/stroke & $150(29.3)$ & $76(28.1)$ & $74(30.6)$ & 0.546 \\
\hline Prior PCl/CABG & $19(3.7)$ & $9(3.3)$ & $10(4.1)$ & 0.633 \\
\hline Prior heart failure & $137(25.8)$ & $70(25.9)$ & $62(25.6)$ & 0.937 \\
\hline Peptic ulcer & $197(38.5)$ & $112(41.5)$ & $85(35.1)$ & 0.140 \\
\hline Asthma/COPD & $22(4.3)$ & $13(4.8)$ & $9(3.7)$ & 0.542 \\
\hline \multicolumn{5}{|l|}{ Hospital findings, n (\%) } \\
\hline Killip class II-IV & $61(11.9)$ & $11(4.1)$ & $50(20.7)$ & $<0.001$ \\
\hline eGFR $<60 \mathrm{~mL} / \mathrm{min} / 1.73 \mathrm{~m}^{2}$ & $223(43.6)$ & $111(41.1)$ & $112(46.3)$ & 0.239 \\
\hline eGFR $<30 \mathrm{~mL} / \mathrm{min} / 1.73 \mathrm{~m}^{2}$ & $29(5.7)$ & $15(5.6)$ & $14(5.8)$ & 0.911 \\
\hline Heart rate< 60 beats/min & $30(5.9)$ & $12(4.4)$ & $18(7.4)$ & 0.150 \\
\hline $\mathrm{SBP}<100 \mathrm{~mm} \mathrm{Hg}$ & $56(10.9)$ & $11(4.1)$ & $45(18.6)$ & $<0.001$ \\
\hline LVEF $<40 \%$ & $57(11.1)$ & $10(3.7)$ & $47(19.4)$ & $<0.001$ \\
\hline AV block II-III & $7(1.4)$ & $5(1.9)$ & $2(0.8)$ & $0.455 \ddagger$ \\
\hline AST/ALT increased & $84(16.4)$ & $43(15.9)$ & $41(16.9)$ & 0.757 \\
\hline In-hospital Gl bleeding & $11(2.1)$ & $7(2.6)$ & $4(1.7)$ & 0.464 \\
\hline \multicolumn{5}{|l|}{ Discharge diagnosis, n (\%) } \\
\hline NSTEACS & $351(68.6)$ & $186(68.9)$ & $165(68.2)$ & 0.863 \\
\hline STEACS & $161(31.4)$ & $84(31.1)$ & 77 (31.98) & \\
\hline \multicolumn{5}{|l|}{ In-hospital revascularisation procedures, n (\%) } \\
\hline No PCl & $384(75.0)$ & $218(80.7)$ & $166(68.6)$ & 0.002 \\
\hline $\mathrm{PCl}$ & $128(25.0)$ & $52(19.3)$ & 76 (31.4) & \\
\hline
\end{tabular}

*Using the $\chi^{2}$ test if other tests were not mentioned.

†Using Mann-Whitney test.

¥Using Fisher's exact test.

ACS, acute coronary syndrome; AST/ALT, aspartate aminotransferase or alanine aminotransferase; AV, atrial ventricular; CABG, coronary artery bypass grafting; CAD, coronary artery disease; eGFR, estimated glomerular filtration rate; GI, gastrointestinal; LVEF, left ventricular ejection fraction; MI, myocardial infarction; NSTACS, non-ST-elevation acute coronary syndrome; PCl, percutaneous coronary intervention; SBP, systolic blood pressure; STEACS, ST-elevation acute coronary syndrome.

to guidelines might also influence our findings. Further studies in a larger number of hospitals should consider the effect of covariates related to hospital and physician characteristics on the association between guideline adherence and patients' major adverse outcomes. Third, we only had information on all-cause mortality and the reason of readmission based on patient interviews. Cause-specific mortality/readmission was not 
Table 3 Factor associated with 6-month major adverse outcomes

\begin{tabular}{lccc}
\hline Factor & $\mathbf{H R}^{\boldsymbol{}}$ & $\mathbf{9 5 \%} \mathbf{C l}$ & $\mathbf{p ~ V a l u e}$ \\
\hline $\begin{array}{l}\text { In-hospital guideline } \\
\text { adherence }\end{array}$ & 0.71 & 0.51 to 0.98 & $\mathbf{0 . 0 3 9}$ \\
$\begin{array}{l}\text { Percutaneous coronary } \\
\text { intervention }\end{array}$ & 0.60 & 0.38 to 0.94 & $\mathbf{0 . 0 2 4}$ \\
$\begin{array}{l}\text { Prior heart failure } \\
\text { Renal insufficiency }\end{array}$ & 1.92 & 1.36 to 2.69 & $<\mathbf{0 . 0 0 1}$ \\
\hline
\end{tabular}

*Using multivariable backward stepwise Cox regression models.

First model: variables entered at the first step: age, gender, number of $\mathrm{CAD}$ risk factors, prior $\mathrm{Ml} /$ stroke, prior heart failure, Killip class II-IV, renal insufficiency, SBP $<100 \mathrm{~mm} \mathrm{Hg}, \mathrm{LVEF}<40 \%$, in-hospital guideline adherence, discharge diagnosis, $\mathrm{PCl}$ and health insurance. Second model: variables entered at the first step: in-hospital guideline adherence, percutaneous coronary intervention, prior heart failure, renal insufficiency and interaction terms: in-hospital guideline adherence and percutaneous coronary intervention, in-hospital guideline adherence and prior heart failure, in-hospital guideline adherence and renal insufficiency.

CAD, coronary artery disease; LVEF, left ventricular ejection fraction; MI, myocardial infarction; $\mathrm{PCl}$, percutaneous coronary intervention; SBP, systolic blood pressure.

possible to assess in our study as patients were readmitted to different hospitals. It was outside the scope of our study to collect data from these hospitals. Fourth, although we attempted to address postdischarge adverse outcomes by adjusting for potential factors, the possibility of confounding by unmeasured covariates such as other comorbidities or ECG characteristics remains. Fifth, estimation of the sample size was not possible because previous studies identifying the association between in-hospital guideline adherence and postdischarge major adverse outcomes in low-income and middle-income countries like Vietnam were not

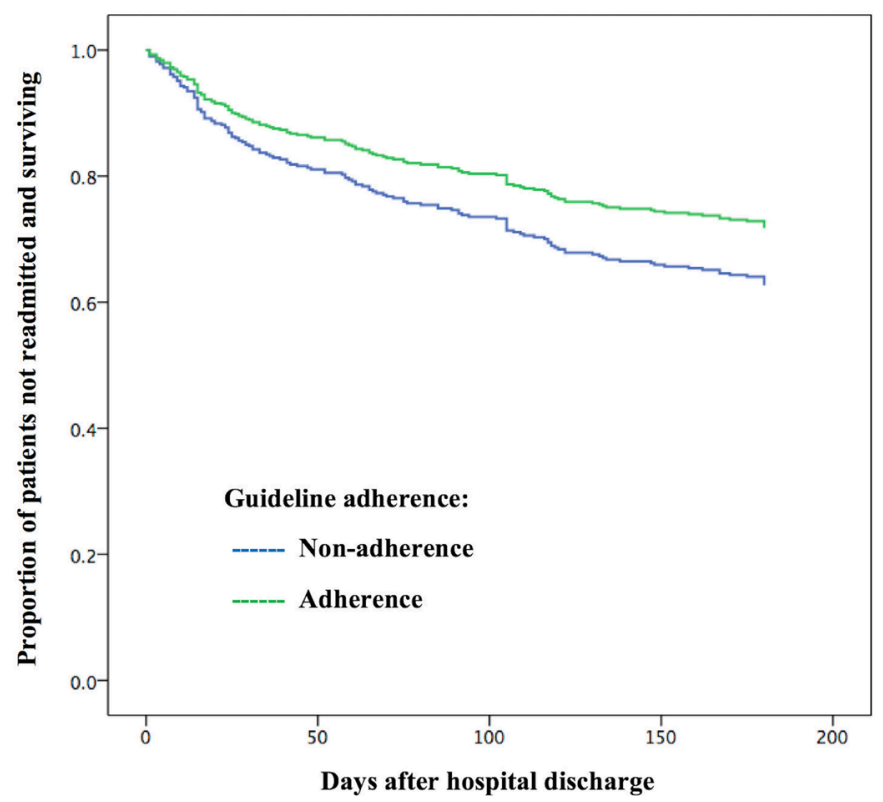

Figure 2 Kaplan-Meier curves for two groups associated with major adverse outcomes 
available. Sixth, we excluded a substantial proportion of patients at baseline because of predefined exclusion criteria. The quality of treatment for these patients, especially for patients who were severely ill or who were transferred to another hospital, could be addressed in future studies. Finally, there was a substantial proportion of dropouts during follow-up. Although baseline characteristics and the proportion of patients receiving in-hospital guideline adherence between dropouts and patients completing the study were similar, there were several considerable differences. However, the results of sensitivity analyses all confirmed the significant impact of in-hospital guideline adherence on 6-month major adverse outcomes.

\section{Possible explanations and comparison with other studies}

Physician adherence to prescribing guideline-recommended medications in Vietnam was suboptimal, lower than other countries' figures with more than two-third being adherent to guidelines. ${ }^{49-51}$ This could explain the high rate of 6-month major adverse outcomes of patients with ACS in Vietnam (about one-third) which was higher than the figures in other countries. ${ }^{52} 53$ The impact of in-hospital guideline adherence on improved 6-month major adverse outcomes could be the result of several mechanisms. First, appropriately prescribing guideline-recommended medications may result in less myocardial damage, which improves postdischarge outcomes among those surviving to hospital discharge..$^{5-9}$ Our findings also showed that patients without major adverse outcomes were more likely to receive betablockers (vs not receive), or all four guideline-recommended medications (vs $<4$ medications) during hospitalisation. However, less than one-third of eligible patients received all four medications according to the guidelines in our study which was lower than in other studies. ${ }^{45455}$ Further studies could investigate associated factors and benefits of receiving all four medications or beta-blockers in our patient group in Vietnam. Also, the application of PCI may have an impact on the medications prescribed according to guidelines; both strategies were known to reduce mortality. ${ }^{42} 4951$ The initiation of PCI and the medications at the index hospitalisation are also a predictor of their consistent use during the follow-up period, an important contributor to the reduction of postdischarge adverse outcomes. ${ }^{42}{ }^{43}$ The risk reduction persists to 6 months after discharge, suggesting that prescribing guideline-recommended medications at the index hospitalisation continues to modulate outcomes. Our findings are consistent with previous studies reporting that guideline adherence during hospitalisation was associated with a significant decrease in postdischarge adverse outcomes, ranging from $10 \%$ to $55 \% .^{495156}$ The results are difficult to compare due to considerable differences such as (1) measuring physician adherence at discharge 444656 or during hospitalisation $^{4545157}$; (2) prescribing of individual medications ${ }^{45}$ or different composites ${ }^{44} 4649-515657$; (3) measuring guideline adherence with ${ }^{45} 5657$ or without ${ }^{44} 4649-51$ including invasive procedures; (4) measuring different adverse outcomes such as death, ${ }^{4143-45495058}$ readmission to hospital, ${ }^{56}$ occurrence of major adverse events ${ }^{50}$ or their combination ${ }^{56}$; (5) different follow-up periods such as 6 months, ${ }^{4456} 1$ year ${ }^{454650515657}$ or longer ${ }^{49} 51$; and (6) the analyses adjusting for different covariates.

\section{CONCLUSIONS AND IMPLICATIONS}

We found that in-hospital guideline adherence was associated with a significant decrease in 6-month major adverse outcomes of patients with ACS in Vietnam. The data strongly support the need for continued efforts to improve adherence to guidelines and confirm the importance of evidence-based medicine in usual clinical care. These findings could also stimulate efforts to implement system strategies to reduce excess mortality and avoidable readmissions. It argues for further studies of the effectiveness of guideline adherence in other healthcare settings, especially in low-income and middle-income countries.

\section{Author affiliations}

${ }^{1}$ Department of Pharmacology and Clinical Pharmacy, Faculty of Pharmacy, Can Tho University of Medicine and Pharmacy, Can Tho, Vietnam

${ }^{2}$ Groningen Research Institute of Pharmacy, Unit of PharmacoTherapy, Epidemiology \& Economics, University of Groningen, Groningen, The Netherlands

${ }^{3}$ Cardiac Ward, Can Tho General Hospital, Can Tho, Vietnam

${ }^{4}$ Cardiac Ward, Can Tho Central General Hospital, Can Tho, Vietnam

${ }^{5}$ Department of Clinical Pharmacy, School of Pharmacy, University of Medicine and Pharmacy at Ho Chi Minh City, Ho Chi Minh, Vietnam

${ }^{6}$ Faculty of Public Health, Can Tho University of Medicine and Pharmacy, Can Tho, Vietnam

Contributors TN, KKL, HTKC and KT were responsible for the study concept and study design. TN, DTTT, LMH and TNDT were involved in data acquisition. All authors (TN, KKL, HTKC, DTTT, LMH, TNDT, HTKP, PTP, THN, EH, TTP and KT) were involved in analysis and interpretation of data. TN and KT drafted the manuscript, and all authors revised it critically for important intellectual content. All authors read and approved the final manuscript. TN and KT are guarantors and take full responsibility for the integrity of the data and the accuracy of the data analysis.

Funding This study was supported by the Vietnam International Education Development via the Project of Training Lecturers with PhD Degree for Universities and Colleges in the period from 2010 to 2020 (Project 911).

Competing interests All authors have completed the ICMJE uniform disclosure form at www.icmje.org/coi_disclosure.pdf (available on request from the corresponding author) and declare: no support from any organisation for the submitted work; no financial relationships with any organisations that might have an interest in the submitted work in the previous three years; no other relationships or activities that could appear to have influenced the submitted work.

\section{Patient consent Obtained.}

Ethics approval The study was approved by the institutional review boards of the Can Tho Central General Hospital and Can Tho General Hospital in Can Tho City, Vietnam. Verbal consent was obtained from all participants.

Provenance and peer review Not commissioned; externally peer reviewed.

Data sharing statement No additional data available.

Open Access This is an Open Access article distributed in accordance with the Creative Commons Attribution Non Commercial (CC BY-NC 4.0) license, which permits others to distribute, remix, adapt, build upon this work non-commercially, and license their derivative works on different terms, provided the original work is properly cited and the use is non-commercial. See: http://creativecommons.org/ licenses/by-nc/4.0/ 
(c) Article author(s) (or their employer(s) unless otherwise stated in the text of the article) 2017. All rights reserved. No commercial use is permitted unless otherwise expressly granted.

\section{REFERENCES}

1. World Health Organization. The top 10 causes of death. 2017, 2017.

2. Finegold JA, Asaria P, Francis DP. Mortality from ischaemic heart disease by country, region, and age: statistics from World Health Organisation and United Nations. Int J Cardiol 2013;168:934-45.

3. Moran AE, Forouzanfar MH, Roth GA, et al. Temporal trends in ischemic heart disease mortality in 21 world regions, 1980 to 2010: the Global Burden of Disease 2010 study. Circulation 2014;129:1483-92.

4. Vietnam Ministry of Health. Vietnam health statistical profile 20092013. Vietnam Ministry of Health 2013.

5. Amsterdam EA, Wenger NK, Brindis RG, et al. AHA/ACC Guideline for the management of patients with non-ST-elevation acute coronary syndromes. Circulation 2014:426:130:e344.

6. O'Gara PT, Kushner FG, Ascheim DD, et al. ACCF/AHA Guideline for the management of ST-elevation myocardial infarction. Circulation 2013:425:127-e362.

7. Roffi M, Patrono C, Collet J, et al. ESC Guidelines for the management of acute coronary syndromes in patients presenting without persistent ST-segment elevation. Eur Heart $J$ 20152016;315:37-267.

8 Steg PG, James SK, Atar D, et al. ESC Guidelines for the management of acute myocardial infarction in patients presenting with ST-segment elevation. Eur Heart J 2012;33:619-2569.

9. Vietnam National Heart Association. The 2008 recommendations on the cardiovascular and metabolic diseases. Ha Noi, Vietnam: Vietnamese Medical Publishing House, 2008.

10. Bhatt DL, Steg PG, Ohman EM, et al. International prevalence, recognition, and treatment of cardiovascular risk factors in outpatients with atherothrombosis. JAMA 2006;295:180-9.

11. Engel J, Damen NL, van der Wulp I, Wulp vander I, et al. Adherence to Cardiac Practice Guidelines in the Management of Non-STElevation Acute Coronary Syndromes: A Systematic Literature Review. Curr Cardiol Rev 2017;13:3-27.

12. Lee HY, Cooke CE, Robertson TA. Use of secondary prevention drug therapy in patients with acute coronary syndrome after hospital discharge. J Manag Care Pharm 2008;14:271-80.

13. Newby LK, LaPointe NM, Chen AY, et al. Long-term adherence to evidence-based secondary prevention therapies in coronary artery disease. Circulation 2006;113:203-12.

14. Fox KA, Goodman SG, Klein W, et al. Management of acute coronary syndromes. Variations in practice and outcome; findings from the Global Registry of Acute Coronary Events (GRACE). Eur Heart $J$ 2002;23:1177-89.

15. Shimony A, Grandi SM, Pilote L, et al. Utilization of evidence-based therapy for acute coronary syndrome in high-income and low/ middle-income countries. Am J Cardiol 2014;113:793-7.

16. Yusuf S, Islam S, Chow CK, et al. Use of secondary prevention drugs for cardiovascular disease in the community in high-income, middleincome, and low-income countries (the PURE Study): a prospective epidemiological survey. Lancet 2011;378:1231-43.

17. Nguyen T, Nguyen TH, Pham HT, et al. Physicians' adherence to acute coronary syndrome prescribing guidelines in Vietnamese hospital practice: a cross-sectional study. Trop Med Int Health 2015;20:627-37.

18. Eagle KA, Montoye CK, Riba AL, et al. Guideline-based standardized care is associated with substantially lower mortality in medicare patients with acute myocardial infarction: the American College of Cardiology's Guidelines Applied in Practice (GAP) Projects in Michigan. J Am Coll Cardiol 2005;46:1242-8.

19. Horning KK, Hoehns JD, Doucette WR. Adherence to clinical practice guidelines for 7 chronic conditions in long-term-care patients who received pharmacist disease management services versus traditional drug regimen review. J Manag Care Pharm 2007;13:28-36.

20. Libungan B, Stensdotter L, Hjalmarson A, et al. Secondary prevention in coronary artery disease. Achieved goals and possibilities for improvements. Int J Cardiol 2012;161:18-24.

21. Setoguchi S, Glynn RJ, Avorn J, et al. Improvements in longterm mortality after myocardial infarction and increased use of cardiovascular drugs after discharge: a 10-year trend analysis. J Am Coll Cardiol 2008:51:1247-54

22. Wijeysundera HC, Machado M, Farahati F, et al. Association of temporal trends in risk factors and treatment uptake with coronary heart disease mortality, 1994-2005. JAMA 2010;303:1841-7.
23. Peterson ED, Roe MT, Mulgund J, et al. Association between hospital process performance and outcomes among patients with acute coronary syndromes. JAMA 2006;295:1912-20.

24. World Health Organization. International statistical classification of diseases and related health problems 10th revision (ICD-10)-WHO Version for 2016, 2016:2016.

25. Goldberg RJ, McCormick D, Gurwitz JH, et al. Age-related trends in short- and long-term survival after acute myocardial infarction: a 20-year population-based perspective (1975-1995). Am J Cardiol 1998;82:1311-7.

26. Stone $\mathrm{PH}$, Thompson $\mathrm{B}$, Anderson HV, et al. Influence of race, sex, and age on management of unstable angina and non-Q-wave myocardial infarction: The TIMI III registry. JAMA 1996;275:1104-12.

27. Mak KH, Kark JD, Chia KS, et al. Ethnic variations in female vulnerability after an acute coronary event. Heart 2004;90:621-6.

28. Vaccarino V, Parsons L, Peterson ED, et al. Sex differences in mortality after acute myocardial infarction: changes from 1994 to 2006. Arch Intern Med 2009;169:1767-74.

29. McManus DD, Gore J, Yarzebski J, et al. Recent trends in the incidence, treatment, and outcomes of patients with STEMI and NSTEMI. Am J Med 2011;124:40-7.

30. Yan AT, Tan M, Fitchett D, et al. One-year outcome of patients after acute coronary syndromes (from the Canadian Acute Coronary Syndromes Registry). Am J Cardiol 2004;94:25-9.

31. Dönges K, Schiele R, Gitt A, et al. Incidence, determinants, and clinical course of reinfarction in-hospital after index acute myocardia infarction (results from the pooled data of the maximal individual therapy in acute myocardial infarction [MITRA], and the myocardial infarction registry [MIR]). Am J Cardiol 2001;87:1039-44.

32. Roe MT, Chen AY, Thomas L, et al. Predicting long-term mortality in older patients after non-ST-segment elevation myocardial infarction: the CRUSADE long-term mortality model and risk score. Am Heart $J$ 2011:162:875-83. e1.

33. Jani SM, Montoye C, Mehta R, et al. Sex differences in the application of evidence-based therapies for the treatment of acute myocardial infarction: the American College of Cardiology's Guidelines Applied in Practice projects in Michigan. Arch Intern Med 2006;166:1164-70

34. Rogers AM, Ramanath VS, Grzybowski M, et al. The association between guideline-based treatment instructions at the point of discharge and lower 1-year mortality in Medicare patients after acute myocardial infarction: the American College of Cardiology's Guidelines Applied in Practice (GAP) initiative in Michigan. Am Heart J 2007:154:461-9.

35. Sanchis J, Núñez J, Bodí V, et al. Influence of comorbid conditions on one-year outcomes in non-ST-segment elevation acute coronary syndrome. Mayo Clin Proc 2011;86:291-6.

36. Yan RT, Yan AT, Tan M, et al. Underuse of evidence-based treatment partly explains the worse clinical outcome in diabetic patients with acute coronary syndromes. Am Heart J 2006;152:676-83.

37. Canto JG, Kiefe Cl, Rogers WJ, et al. Number of coronary heart disease risk factors and mortality in patients with first myocardial infarction. JAMA 2011;306:2120-7.

38. Khot UN, Jia G, Moliterno DJ, et al. Prognostic importance of physical examination for heart failure in non-ST-elevation acute coronary syndromes: the enduring value of Killip classification. JAMA 2003;290:2174-81.

39. Steg PG, Dabbous OH, Feldman LJ, et al. Determinants and prognostic impact of heart failure complicating acute coronary syndromes: observations from the Global Registry of Acute Coronary Events (GRACE). Circulation 2004;109:494-9.

40. Goldberg RJ, Gore JM, Alpert JS, et al. Cardiogenic shock after acute myocardial infarction. Incidence and mortality from a community-wide perspective, 1975 to 1988. N Engl J Med 1991;325:1117-22.

41. Bahit MC, Lopes RD, Clare RM, et al. Heart failure complicating nonST-segment elevation acute coronary syndrome: timing, predictors, and clinical outcomes. JACC Heart Fail 2013;1:223-9.

42. Butler J, Arbogast PG, BeLue R, et al. Outpatient adherence to betablocker therapy after acute myocardial infarction. J Am Coll Cardiol 2002;40:1589-95.

43. Butler J, Arbogast PG, Daugherty J, et al. Outpatient utilization of angiotensin-converting enzyme inhibitors among heart failure patients after hospital discharge. J Am Coll Cardiol 2004;43:2036-43.

44. Chew DP, Anderson FA, Avezum A, et al. Six-month survival benefits associated with clinical guideline recommendations in acute coronary syndromes. Heart 2010;96:1201-6.

45. Levy CR, Radcliff TA, Williams ET, et al. Acute myocardial infarction in nursing home residents: adherence to treatment guidelines reduces mortality, but why is adherence so low? J Am Med Dir Assoc 2009;10:56-61. 
46. Yan AT, Yan RT, Tan M, et al. Optimal medical therapy at discharge in patients with acute coronary syndromes: temporal changes, characteristics, and 1-year outcome. Am Heart J 2007;154:1108-15.

47. Vietnam National Heart Association. Consensus of experts on betablockers in cardiovascular diseases and internal medicine. Ho Chi Minh city, Vietnam: Vietnamese Medical Publishing House, 2010.

48. López-Sendón J, Swedberg K, McMurray J, et al. Expert consensus document on beta-adrenergic receptor blockers. Eur Heart $J$ 2004;25:1341-62.

49. Allen LA, O'Donnell CJ, Giugliano RP, et al. Care concordant with guidelines predicts decreased long-term mortality in patients with unstable angina pectoris and non-ST-elevation myocardial infarction Am J Cardiol 2004;93:1218-22.

50. Bauer T, Gitt AK, Jünger $\mathrm{C}$, et al. Guideline-recommended secondary prevention drug therapy after acute myocardial infarction: predictors and outcomes of nonadherence. Eur J Cardiovasc Prev Rehabil 2010;17:576-81.

51. Shah BR, O'Brien EC, Roe MT, et al. The association of in-hospital guideline adherence and longitudinal postdischarge mortality in older patients with non-ST-segment elevation myocardial infarction. Am Heart J 2015;170:273-80. e1.

52. Fox KA, Dabbous OH, Goldberg RJ, et al. Prediction of risk of death and myocardial infarction in the six months after presentation with acute coronary syndrome: prospective multinational observational study (GRACE). BMJ 2006;333:1091.

53. Xu H, Wiviott SD, Sabatine MS, et al. Outcomes and readmission rate within 30 days and 6 months after acute myocardial infarction in China: Data from the china acute myocardial infarction registry,. JACC 2016:67:-506.

54. Berwanger O, Guimarães HP, Laranjeira LN, et al. Effect of a multifaceted intervention on use of evidence-based therapies in patients with acute coronary syndromes in Brazil: the BRIDGE-ACS randomized trial. JAMA 2012;307:2041-9.

55. McAlister FA, Fradette M, Majumdar SR, et al. The Enhancing Secondary Prevention in Coronary Artery Disease trial. CMAJ 2009;181:897-904.

56. Stukel TA, Alter DA, Schull MJ, et al. Association between hospital cardiac management and outcomes for acute myocardial infarction patients. Med Care 2010;48:157-65.

57. Schiele F, Meneveau N, Seronde MF, et al. Compliance with guidelines and 1-year mortality in patients with acute myocardia infarction: a prospective study. Eur Heart $J$ 2005;26:873-80.

58. Kolansky DM. Acute coronary syndromes: morbidity, mortality, and pharmacoeconomic burden. Am J Manag Care 2009;15:S36-41. 